ment now proposed rests on the changes that have since taken place. China has indeed joined IAEA. Chinese officials are reported to have said that Chinese collaboration with nonnuclear weapons states would be subjected to IAEA safeguards (as in the agreement with Brazil on reactor development at the end of last year). But otherwise the administration can offer only quotations from Chinese leaders' public speeches to the effect that China does not "help other countries to develop nuclear weapons". These are hardly assurances of the kind the US Congress expects from the administration's lawyers.

How might this perplexing situation be resolved? The ideal is that China should join the NPT and thus be bound by the obligation not to help others make nuclear weapons. On the face of things, there is no reason why China's present leadership should not be persuaded that such a step would insulate present policies on proliferation from whatever domestic changes may lie ahead. There is some force in the administration's claim that even an unsatisfactory agreement on nuclear cooperation will enable it to influence policy in the years ahead; it should be asked for a reasoned estimate of the chances of Chinese membership of the NPT when it comes to plead its case for the agreement in the coming months. China, of course, may argue that it is no differently placed from France, a nuclear power which has also declined to join the NPT, but that is only partly true; France has formally declared that it will behave as if it were a member, and has joined the Nuclear Suppliers Group (the "London club") to coordinate safeguard policies. That would be a half-way house for China, but is it asking too much that both these black sheep should now be persuaded, by a judicious blend of cajolery and pressure, to join up?

The harder nut to crack stems from the fact that any assistance from outside with the construction and operation of reactors will help China become a fully fledged nuclear power, with plutonium as well as uranium bombs in its arsenals. Is the United States (and other states with cooperation agreements with China - Belgium, Britain and West Germany) reconciled to that prospect? The rest of the world has not yet come to terms with the notion that China is already a nuclear power and will become an even more substantial one. Circumspectly, by seeming not to have a declaratory nuclear strategy, China has helped others to set this question aside. But if British and French nuclear weapons become a factor in the bilateral arms control talks between the Soviet Union and the United States, as they did in the earlier series aborted in 1983, should not China also be counted? And how could that be accomplished without consultation with China, perhaps even its active involvement in the Geneva negotiations? Here again the recent record is far from discouraging; Chinese participation in the UN committee on disarmament (also at Geneva) is generally recognized to have been constructive. If the United States hopes to win influence on China's nuclear policy by means of an agreement falling short of what it wants, may it not expect its influence to work on that wider canvas? That, certainly, is another issue that the US Congress should take up with the custodians of the non-paper agreements with China - before acquiescing, as it must in the end, in the administration's urgent pleas that more harm than good would be done by throwing out the proposed agreement. $\square$

\section{Research responsibility}

Another demand for more UK research funds, but the government ducks responsibility.

THE British basic science problem is becoming a bore, not merely for the vast majority of Nature's readers (who work elsewhere) but even for the British. The House of Commons select committee reporting last week is but the latest in a series of committees recently to have said that basic science in Britain is in danger of collapse for lack of funds. Within the past few months, the Advisory Board for the Research Councils (ABRC) has said so, as have numerous speakers in the recent House of
Commons debate. The opinion is widely shared, and may even be true. Certainly within the present framework, the British government's support for research is inadequate, almost calculated to engender collapse by the erosion of institutions and the spirits of those who work in them. The select committee's report is a model of clarity (and brevity) but says very little that is unfamiliar. Some of its recommendations, such as that the cost of paying research council superannuation should be a separate line item in the government's annual budget (see page 384), seem almost to have been designed as a convenience to Sir Keith Joseph, believed himself to have been converted to the view that there should be more money. Why, in these circumstances, does nothing happen?

The most arresting line in the select committee's report is that, as things are, and without more money for basic research, the "government will not achieve its own objective" of keeping British basic science vigorous. That could have been the committee's text, and it should have made more of it. The British government's attitude during the past six years towards the cost of research has been that it is for the scientific community to manage its own affairs within a budget which has, if anything, increased in real terms, although not by much. If the community then makes a hash of the job, it only has itself to blame. In exactly the same spirit might parents ask a child to clothe himself on a monthly allowance, and then say it is no fault of theirs that he has spent so much on what is called gear that he has no shoes to wear to school? One obvious respect in which the analogy is not exact is that in the management of research, the scientific community and the government have an interest in keeping research healthy: the government's wider objectives will be unattainable if the system collapses. That is why it cannot suffice for government to stick to its policy of constant budgets without caring for the consequences.

A particular and long-familiar set of issues will illustrate the problem. Three of the four science-based research councils have traditionally carried out a large proportion of their research in their own institutes, while the fourth has recently gone part of the way down that road in the belief that this is an economical way of providing academic researchers with expensive central facilities. Nature has long held that the arrangement robbed the councils of flexibility, but it stems from the time, at least in agriculture and medicine, when the universities collectively were not a viable alternative; more recently (in 1972), it was sanctified by the Rothschild proposals for the organization of basic science, which made in-house research institutes natural repositories of government commissions of applied research. But now, in changed circumstances, it is clear that the councils are over-committed to in-house institutes, which seem especially inflexible at times of rapid change and which may also be more expensive ways of getting work done than are university and polytechnic departments, crying out for research projects as they are. The councils are eager to take advantage of the new opportunities, but are prevented from doing so by the high cost of "restructuring", a euphemism for letting people go.

So who is to blame? The British government in its present mood would shrug its shoulders and say that the councils should not have let themselves get into this position in the first place. But how proper is it for a government to wash its hands of responsibility for a situation in which its predecessors have connived, however unreflectively? And even if it were that the present state of affairs could be called bad management by the scientific community in earlier decades, how can that knowledge absolve the present government from the responsibility (and present interest) in the preservation of a healthy science enterprise? Does one deny a spendthrift child the shoes he needs to wear to school? The reality, as the governments of France, Japan and the United States have recognized, is that this is a time in the development of technology when, paradoxically, it pays to spend more on basic science. But none of that means, as the select committee implies, that the problems of organization can be left on one side. Why not, for a change, solve two problems at once? 